\title{
Smoking cessation after an acute coronary syndrome: immediate quitters are successful quitters
}

\author{
M. Snaterse · W.J.M. Scholte op Reimer · J. Dobber · \\ M. Minneboo - G. ter Riet - H.T. Jorstad • \\ S.M. Boekholdt $\cdot$ R.J.G. Peters
}

Published online: 8 October 2015

(C) The Author(s) 2015. This article is published with open access at Springerlink.com

\begin{abstract}
Background Cardiovascular disease (CVD) prevention guidelines stress the importance of smoking cessation and recommend intensive follow-up. To guide the development of such cessation support strategies, we analysed the characteristics that are associated with successful smoking cessation after an acute coronary syndrome (ACS).

Methods We used data from the Randomised Evaluation of Secondary Prevention for ACS patients coordinated by Outpatient Nurse SpEcialists (RESPONSE) trial $(n=754)$. This was designed to quantify the impact of a nurse-coordinated prevention program, focusing on healthy lifestyles, traditional CVD risk factors and medication adherence. For the current analysis we included all smokers (324/754, 43\%). Successful quitters were defined as those who reported abstinence at 1 year of follow-up.

Results The majority of successful quitters quit immediately after the ACS event and remained abstinent through 1 year of follow-up, without extra support (128/156, 82\%). Higher education level ( 33 vs. $15 \%, p<0.01$ ), no history of CVD ( 87 vs. $74 \%, p<0.01)$ and being on target for LDL-
\end{abstract}

\footnotetext{
M. Snaterse $(\bowtie) \cdot$ W.J.M. Scholte op Reimer · J. Dobber University of Applied Sciences, Hogeschool van Amsterdam, Amsterdam School of Health Professions,

Tafelbergweg 51,

1105 BD Amsterdam, The Netherlands

e-mail: m.snaterse@hva.nl
}

M. Minneboo · H.T. Jorstad · S.M. Boekholdt · R.J.G. Peters Department of Cardiology, Academic Medical Center, Amsterdam, The Netherlands

G. ter Riet

Department of General Practice,

Academic Medical Center, University of Amsterdam,

Amsterdam, The Netherlands cholesterol level at 1 year (78 vs. $63 \%, p<0.01)$ were associated with successful quitting.

Conclusion The majority of successful quitters at 1 year stopped immediately after their ACS. Patients in this group showed that it was within their own ability to quit, and they did not relapse through 1 year of follow-up. Our study indicates that in a large group of patients who quit immediately after a life-threatening event, no relapse prevention program is needed.

Keywords Acute coronary syndrome - Smoking cessation · Secondary prevention

\section{Introduction}

Coronary heart disease (CHD) patients are at high risk of recurrent coronary events and mortality. Risk reduction strategies are therefore offered to patients with established CHD or other atherosclerotic cardiovascular disease (CVD). Smoking is known to be a major health risk factor $[1,2]$. Smoking cessation after CHD is diagnosed is potentially the most effective preventive measure. It is associated with a $33 \%-50 \%$ reduction in risk of recurrent myocardial infarctions or cardiovascular death [3-5] and a life expectancy gain of 3 years after coronary artery bypass surgery [6]. Nevertheless, although smoking cessation is potentially the most effective CVD prevention strategy, quitting smoking is difficult and secondary prevention is suboptimal. Studies from Europe and the USA have shown that half of the patients continue to smoke despite a life-threatening event $[7,8]$. Although the majority received personal advice to stop or were offered counselling, many were not able to quit $[7,9]$. In general, surveys revealed a disappointing situation with regard to secondary prevention actions. A substantial 


\title{
Advertisement placed here.
}

\author{
CSS Bohn

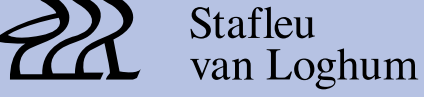 \\ Springer Media
}

Houten 2015 


\title{
Advertisement placed here.
}

\author{
CSS Bohn

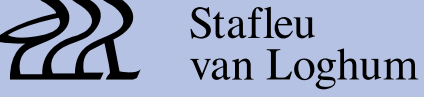 \\ Springer Media
}

Houten 2015 
potential to reduce the risk of recurrent cardiovascular disease or death still remains.

Successful strategies for smoking cessation include pharmacological therapy (nicotine replacement therapy, bupropion and varenicline) and behavioural counselling for smokers willing to quit [10-12] Successful behavioural support in smoking cessation has been reported for group therapy, individual counselling [11] and telephone counselling [13] and to a lesser extent for individually tailored self-help materials [11]. In addition, guidelines on CVD prevention recommend frequent follow-up visits for all smokers who have quit to increase long-term success [14]. However, as shown in a recent review [15], the effectiveness of behavioural relapse prevention methods for any initially successful subgroup of former smokers has not been demonstrated.

Nurse-coordinated prevention programs also aim to increase the proportion of patients achieving CVD prevention targets, but these initiatives have not resulted in higher smoking cessation rates [16-19]. With the RESPONSE trial we evaluated whether a nurse-coordinated prevention program leads to better achievement of guideline-recommended CVD prevention targets [20]. We found this program improved blood pressure and lipid management, but did not have a significant impact on lifestyle factors, including smoking cessation [20].

It is currently unknown which patients benefit from intensive smoking cessation counselling after hospital admission for acute coronary syndrome (ACS). Better understanding of the characteristics of patients who are likely to quit successfully after ACS may provide useful information to guide development of more effective smoking cessation interventions. We therefore addressed the following research question: what are the characteristics of successful quitters after a recent ACS?

\section{Methods}

Design and study population

The RESPONSE trial $(n=754)$ was a multicentre, randomised controlled trial conducted in 11 centres in the Netherlands with 1 year of follow-up. Patients aged 18-80 years were eligible if they had been diagnosed and hospitalised with ACS within 8 weeks prior to enrolment in the trial. Patients were excluded if they (1) were unable to visit the nurse-coordinated prevention program, (2) were not available for follow-up, (3) had a limited life expectancy ( $\leq 2$ years), and (4) were diagnosed with a New York Heart Association class III or class IV heart failure. Patients were randomised to either the nurse-coordinated prevention program or usual care alone. Detailed information about the study methods has been reported elsewhere [20, 21]. For the current analyses, we selected 324 patients who smoked before the index ACS event (43\%) and reported a smoking and quitting status at 1 year of follow-up.

We defined successful quitters as patients who reported abstinence accompanied by a quit date at 1 year of followup. We defined relapsers as those patients who had attempted to quit smoking but reported that they began smoking again within 1 year, and were therefore classified as 'smoker' in the main analysis at 1 year of follow-up. Patients who reported that they continued smoking in the year of followup were also classified as smokers.

Data collection and follow-up

Baseline measurements were performed within 8 weeks after ACS. Patients were enrolled at an average of 4 weeks (SD 2.7). Patients in the intervention group visited the outpatient clinic four times during the first 6 months after inclusion, in addition to visits to their treating cardiologist (usual care). During each nurse visit cardiovascular risk factors were evaluated. Data on clinical and demographic characteristics, CHD risk factors and smoking quit dates were collected at baseline and follow-up. Smoking behaviour was measured by means of interview questions. Health-related quality of life was assessed with the MacNew questionnaire $[22,23]$. Scores on each quality of life domain were calculated as the average of the responses in that domain. We used the Systematic Coronary Risk Evaluation (SCORE) as an integrated measure to estimate the overall impact of smoking cessation on cardiovascular risk.

\section{Statistical analysis}

The results of our statistical analysis are presented as absolute numbers and percentages. Differences between successful quitters and smokers were analysed by using unpaired t-tests for continuous variables and chi-square statistics for categorical variables. We used SPSS (version 20.0) for all data analysis.

\section{Results}

Of 324 smokers admitted to hospital with ACS, 186 (57\%) reported a cessation attempt in the year after the event. Of those, $156(86 \%)$ were successful quitters in up to 1 year of follow-up. The majority of this group quit immediately after the event (128/156, 82\%; Fig. 1) and received no smoking cessation counselling after discharge. Patients making a later cessation attempt were less successful in quitting smoking $(28 / 44,64 \%)$.

As shown in Table 1, successful quitting up to 1 year after ACS was associated with a higher education level (33 vs. 


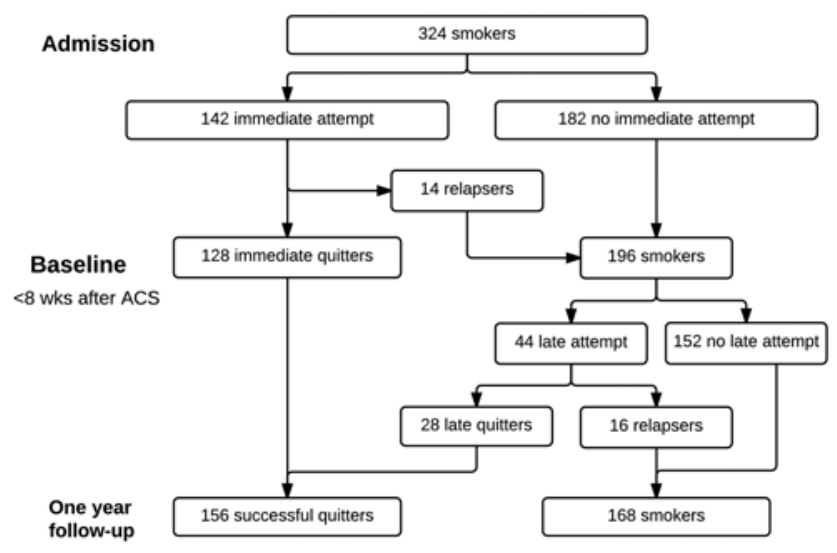

Fig. 1 Flowchart of 324 smokers after an acute coronary syndrome (ACS) from hospital admission up to 1-year follow-up

$15 \%, p<0.01)$, no history of CVD ( 87 vs. $74 \%, p<0.01)$, being on target for LDL-cholesterol level at 1 year (78 vs. $63 \%, p<0.01)$ and adequate physical activity at 1 year $(65$ vs. $52 \%, p=0.01)$.

At 12 months, the estimated SCORE cardiovascular 10 -year mortality risk was $2.9 \%$ (SD 0.03 ) for successful quitters and $5.7 \%$ (SD 0.07) for smokers $(p<0.01)$. Successful quitters and smokers were comparable in other lifestyle risk factors than smoking at baseline, while after 1 year successful quitters more frequently had a body mass index (BMI) $>25 \mathrm{~kg} / \mathrm{m}^{2}$ compared with smokers (81 vs. $67 \%$, $p<0.01$ ) Mean BMI at 1 year was $29.0 \mathrm{~kg} / \mathrm{m}^{2}$ (SD 4.93) in successful quitters and $27.5 \mathrm{~kg} / \mathrm{m}^{2}$ (SD 5.04) in smokers. Smoking cessation after ACS was associated with an average weight gain of $3.36 \mathrm{~kg}$ (SD 5.48) at 1 year. In our study we observed a maximal weight gain in successful quitters of $21 \mathrm{~kg}$, whereas $9 \%$ of successful quitters gained $>10 \mathrm{~kg}$ after smoking cessation.

Within the group of smokers, $63 \%$ reduced smoking cigarettes at 1 year of follow-up compared with baseline level. These patients had a higher level of education and smoked a higher number of cigarettes per day compared with smokers not reducing cigarette smoking. We observed a median reduction of 5 (IQR $0-15$ ) cigarettes for smokers at 1 year of follow-up. In smokers who reduced cigarette smoking, we found that after 1 year they smoked a median of 13 cigarettes (IQR 6-20) less than at baseline.

In total, 30 relapsers were presented (Table 1). The majority $(90 \%)$ of these were younger than 60 years of age, relatively more were female $(33 \%)$ than both successful quitters and smokers and diagnosed with ST-segmentelevation myocardial infarction $(60 \%)$. We found that a group of 14 relapsers before baseline measurements were predominantly male coronary artery bypass graft (CABG) patients $(86 \%)$.

Of 44 patients making later cessation attempts, $73 \%$ were in the nurse-coordinated prevention program group.
This group was encouraged to quit smoking and was given information about a healthy lifestyle. However, participation in the nurse-coordinated prevention program group did not significantly increase smoking cessation rates in patients making a late attempt $(p=0.8)$.

\section{Discussion}

Our study demonstrates that immediate cessation after hospitalisation for ACS is the most important characteristic of successful quitters. A higher level of education, no history of CVD, LDL-cholesterol level on target and adequate physical activity at 1 year characterised successful quitters at 1 year after ACS as well. At 1 year, however, successful quitters more often had a BMI $>25 \mathrm{~kg} / \mathrm{m}^{2}$ compared with smokers.

The REPONSE trial showed that a nurse-coordinated prevention program improved systolic blood pressure and blood levels of LDL-cholesterol. However, this program was less successful in achieving smoking cessation [20]. In the current paper we explored characteristics that may increase successful smoking cessation, for smoking is a major risk factor of mortality and recurrent events in CHD patients.

Our study confirms that quitting smoking is extremely difficult for many patients, even after being hospitalised for a life-threatening event, especially for those with a lower education level. Only half of the patients succeeded in quitting smoking after ACS, which is consistent with success rates in previous studies [7, 9].

On the positive side, however, our study also shows that almost half of all smokers succeeded in quitting up to 1 year after ACS. Moreover, of those who quit immediately after the acute event, the majority are successful through 1 year. Our study confirms earlier findings indicating that a clinical event acts as an important motivator and may induce behavioural change [24], particularly if this event is perceived as life-threatening as is the case with patients' first ACS [9, 25]. In accordance with European Society of Cardiology (ESC) guidelines, clinicians may make greater use of this opportunity by addressing the issue before discharge [14]. These guidelines also recommend that support for cessation of smoking is initiated for all smokers during hospital admission and is continued for a prolonged period after discharge $[10,14]$. Our study shows, however, that the majority of successful quitters stop immediately after discharge, triggered by the ACS event, and that it is within their own ability to quit and remain abstinent.

This continued change of behaviour may be explained by the theory of self-perception, which describes how people use their own behaviour to learn what they believe [24]. In our study, during admission almost half of the smokers 
Table 1 Characteristics of successful quitters versus smokers in ACS patients $(n=324)$ Immediate: immediately after hospital discharge; late: during one year of follow-up.

\begin{tabular}{|c|c|c|c|c|}
\hline & Successful quitters $^{\mathrm{a}} n=156$ & Smokers $n=168$ & $P$-value ${ }^{\mathrm{b}}$ & Relapsers $^{\mathrm{c}} n=30$ \\
\hline \multicolumn{5}{|l|}{ Age } \\
\hline$<50$ years & $53(34 \%)$ & $61(36 \%)$ & 0.89 & $14(47 \%)$ \\
\hline $50-59$ years & $67(43 \%)$ & $71(42 \%)$ & & $13(43 \%)$ \\
\hline$\geq 60$ years & $36(23 \%)$ & $36(21 \%)$ & & $3(10 \%)$ \\
\hline Male, $n(\%)$ & $127(81 \%)$ & $125(74 \%)$ & 0.13 & $20(67 \%)$ \\
\hline \multicolumn{5}{|l|}{ Highest level of education, $n(\%)$} \\
\hline Fewer than 8 years & $41(28 \%)$ & $63(38 \%)$ & 0.02 & $13(43 \%)$ \\
\hline College or university & $49(33 \%)$ & $25(15 \%)$ & $<0.001$ & $5(17 \%)$ \\
\hline No history of CVD, $n(\%)$ & $136(87 \%)$ & $124(74 \%)$ & $<0.01$ & $19(63 \%)$ \\
\hline \multicolumn{5}{|l|}{ Index event, $n(\%)$} \\
\hline STEMI & $89(57 \%)$ & $89(53 \%)$ & 0.89 & $18(60 \%)$ \\
\hline NSTEMI & $50(32 \%)$ & $51(30 \%)$ & & $7(23 \%)$ \\
\hline Unstable angina pectoris & $17(11 \%)$ & $26(16 \%)$ & & $4(13 \%)$ \\
\hline Nurse Coordinated Prevention Programme & $89(57 \%)$ & $83(49 \%)$ & 0.17 & $16(53 \%)$ \\
\hline \multicolumn{5}{|l|}{ No. cigarettes/day } \\
\hline$\leq 10$ & $62(40 \%)$ & $59(35 \%)$ & 0.36 & $10(33 \%)$ \\
\hline$>10$ & $93(60 \%)$ & $109(65 \%)$ & & $20(67 \%)$ \\
\hline Quality of life at baseline (mean, SD) & $5.13(1.06)$ & $5.02(1.14)$ & 0.47 & $5.0(0.9)$ \\
\hline Quality of life at 1-year follow-up & $5.66(1.01)$ & $5.46(0.99)$ & 0.66 & $5.6(0.7)$ \\
\hline \multicolumn{5}{|l|}{ Risk factors at baseline } \\
\hline Systolic blood pressure $>140 \mathrm{mmHg}$ & $36(24 \%)$ & $33(20 \%)$ & 0.12 & $4(13 \%)$ \\
\hline LDL-cholesterol $>2.5 \mathrm{mmol} / \mathrm{L}$ & $46(31 \%)$ & $66(39 \%)$ & 0.15 & $13(43 \%)$ \\
\hline Body mass index $>25 \mathrm{~kg} / \mathrm{m}^{2}$ & $116(74 \%)$ & $115(68 \%)$ & 0.12 & $22(73 \%)$ \\
\hline Inadequate physical activity ${ }^{\mathrm{e}}$ & $89(57 \%)$ & $98(58 \%)$ & 0.81 & $16(53 \%)$ \\
\hline \multicolumn{5}{|l|}{ Risk factors at 1-year follow-up } \\
\hline Systolic blood pressure $>140 \mathrm{mmHg}$ & $41(28 \%)$ & $43(26 \%)$ & 0.79 & $9(30 \%)$ \\
\hline LDL-cholesterol $>2.5 \mathrm{mmol} / \mathrm{L}$ & $32(22 \%)$ & $62(37 \%)$ & $<0.01$ & $16(57 \%)$ \\
\hline Body mass index $>25 \mathrm{~kg} / \mathrm{m}^{2}$ & $127(81 \%)$ & $112(67 \%)$ & $<0.01$ & $23(78 \%)$ \\
\hline Inadequate physical activity & $54(35 \%)$ & $81(48 \%)$ & 0.01 & $15(50 \%)$ \\
\hline Systematic Coronary Risk Evaluation (SCORE) & $2.9 \%$ & $5.7 \%$ & $<0.01$ & $4.2 \%$ \\
\hline
\end{tabular}

${ }^{a}$ Defined as non-smoking at outcome assessment date;

${ }^{b}$ Between successful quitters and smokers;

'note that these 30 relapsers are a subgroup of the 168 smokers;

${ }^{\mathrm{d}}$ assessed with the MacNew questionnaire;

${ }^{\mathrm{e}}<30 \mathrm{~min} / 5$ times a week.

showed that they were willing to change and felt able to change. The feeling of being able to change is strengthened when these patients indeed quit smoking after discharge. These patients soon perceive themselves as 'successful quitters' [24], which subsequently strengthens them in their resolve to remain abstinent. Moreover, for these patientswho are in a 'ready for action' stage, according to the stages of change theory of Prochaska and Diclemente [26] - counselling seems unnecessary and may be even counterproductive $[24,27]$. The results of our study therefore suggest that the WHO smoking cessation algorithm, which is included in the ESC guideline and recommends intensive follow-up for all smokers, may not be appropriate for smokers who quit immediately after ACS. In the decision-making process about smoking cessation interventions, a distinction could be made between types of smokers, such as quitters trig- gered by an acute life-threatening event or other triggers and immediate or late quitters. In patients hospitalised for acute events who immediately quit after discharge, and do not relapse up to their first outpatient clinic visit, relapse prevention by counselling or pharmacological therapy may not be necessary. In our study, none of the immediate quitters who remained abstinent up to their first outpatient visit reported a relapse up to 1 year after ACS, and evidence for the effectiveness of relapse prevention for patients who immediately quit smoking after an acute hospitalisation is lacking [15].

Our results are, however, less clear about the effectiveness of smoking cessation interventions at hospital discharge, as we observed a number of relapsers between hospital discharge and the first visit to the outpatient clinic. This occurred particularly in CABG patients, who may feel 
the external pressure not to smoke, but may not be intrinsically motivated to quit or not feeling able to quit. Smoking reduction to support smoking cessation could be considered for smokers who are willing but unable to quit [28]. Reduced smoking can be advised until these patients are ready for a new attempt $[28,29]$. More research is needed on characteristics of ACS patients who intend to quit smoking during hospitalisation, in order to focus on those who are willing to quit but are at risk for relapse after discharge. Our study confirms earlier research showing that successful quitting is strongly associated with a higher education level and no history of CVD [9, 25]. Deferral of smoking cessation interventions after hospital discharge should be considered in patients with these characteristics. In our study, pharmacological support was not part of the smoking cessation counselling, although guidelines recommend offering aids to assist cessation. Nicotine replacement therapy, bupropion and varenicline have been shown to improve the chances of successful quitting, although patients with a recent history of cardiac disease were excluded in these studies $[12,30]$ Therefore, the results of pharmacological studies may not be applied to immediate quitters after an acute event. Regarding relapse prevention, the only medical therapy for which there is compelling evidence is varenicline [15]. More research is needed on the effectiveness of pharmacological aids in immediate quitters after an acute life-threatening event.

Furthermore, since nurses obtained information on smoking quitting dates retrospectively, recall bias may play a role. Successful quitters may remember quitting dates better than smokers who attempted to quit but relapsed. In addition, we may have underestimated the problem of unsuccessful quit attempts, as self-report information is less reliable than measurements of nicotine concentration [31].

Lastly, we observed that successful quitters have an unfavourable risk factor profile after 1 year. Consistent with previous reports, quitters were more often overweight [32, $33]$. We also observed that quitters did not improve on systolic blood pressure targets at 1 year of follow-up compared with their baseline values, despite the fact that they reported being physically more active. It is well known that quitting smoking decreases the metabolic rate, which results in a mean increase of 4-5 $\mathrm{kg}$ in body weight after 12 months $[14,32,33]$. Moreover, some patients exchange one addiction for another, and gain weight after quitting smoking [34]. In fact, the addiction may not be interrupted, but simply replaced by another [34]. Future research is needed to investigate the mechanisms involved and to improve weight loss interventions for this subgroup.

We conclude that the majority of successful quitters stop immediately after their ACS. Patients in this group showed that it was within their own ability to quit, and they did not relapse in 1 year of follow-up. We found no evidence to support the use of relapse prevention in ACS patients who stop smoking immediately after the event, and our study indicates that there is no need for this during followup visits in a large group of patients. The momentum for smoking cessation is particularly strong immediately after ACS and our study reinforces the importance of clinicians' explicit advice to stop smoking during hospitalisation of ACS patients. New strategies are needed in patients with a late attempt. Smoking cessation strategies in secondary prevention could differentiate between acute and non-acute patients, since an acute event acts as an important motivator for behavioural change. Furthermore smoking cessation support should differentiate between immediate and late attempts, since relapse prevention seems unnecessary for immediate quitters. However, patients with a late attempt may benefit from more intensive therapy. Future research is needed to assess the cost-effectiveness of differentiating between acute or non-acute admissions and immediate or late quit attempts.

Funding The RESPONSE trial was sponsored by an unrestricted grant from AstraZeneca, the Netherlands. The sponsor had no role in the design, data collection, data analysis, data interpretation and writing of this report.

Conflicts of interests M. Snaterse, W.J.M. Scholte op Reimer, M. Minneboo, J. Dobber, G. ter Riet, H.T. Jorstad, S.M. Boekholdt and R.J.G. Peters declare no conflict of interest.

Open Access This article is distributed under the terms of the Creative Commons Attribution License which permits any use, distribution, and reproduction in any medium, provided the original author(s) and source are credited.

\section{References}

1. Yusuf S, Hawken S, Ounpuu S, et al. Effect of potentially modifiable risk factors associated with myocardial infarction in 52 countries (the INTERHEART study): case-control study. Lancet. 2004;364:937-52.

2. Jukema JB, Bagnasco DE, Jukema RA. Waterpipe smoking: not necessarily less hazardous than cigarette smoking: Possible consequences for (cardiovascular) disease. Neth Heart J. 2014;22:91-9.

3. Iestra JA, Kromhout D, Schouw YT van der, et al. Effect size estimates of lifestyle and dietary changes on all-cause mortality in coronary artery disease patients: a systematic review. Circulation. 2005;112:924-34.

4. Critchley J, Capewell S. Smoking cessation for the secondary prevention of coronary heart disease. Cochrane Database Syst Rev. 2004; 1:CD003041.

5. Chow CK, Jolly S, Rao-Melacini P, et al. Association of diet, exercise, and smoking modification with risk of early cardiovascular events after acute coronary syndromes. Circulation. 2010;121:750-8

6. Domburg RT van, op Reimer WS, Hoeks SE, et al. Three lifeyears gained from smoking cessation after coronary artery bypass surgery: a 30-year follow-up study. Am Heart J. 2008;56:473-6. 
7. Kotseva K, Wood D, De Backer G, et al. EUROASPIRE III: a survey on the lifestyle, risk factors and use of cardioprotective drug therapies in coronary patients from 22 European countries. Eur J Cardiovasc Prev Rehabil. 2009;16:121-37.

8. Schauer GL, Malarcher AM, Zhang L, et al. Prevalence and correlates of quitline awareness and utilization in the United States: an update from the 2009-2010 National Adult Tobacco Survey. Nicotine \& Tobacco Research 2013.

9. Scholte op Reimer W, Swart E de, De Bacquer D, et al. Smoking behaviour in European patients with established coronary heart disease. Eur Heart J. 2006;27:35-41.

10. Rigotti NA, Clair C, Munafo MR, et al. Interventions for smoking cessation in hospitalised patients. Cochrane Database Syst Rev. 2012;5:CD001837.

11. Stead LF, Lancaster T. Behavioural interventions as adjuncts to pharmacotherapy for smoking cessation. Cochrane Database Syst Rev. 2012;12:CD009670.

12. Stead LF, Perera R, Bullen C, et al. Nicotine replacement therapy for smoking cessation. Cochrane Database Syst Rev. 2012;11:CD000146.

13. Stead LF, Hartmann-Boyce J, Perera R, et al. Telephone counselling for smoking cessation. Cochrane Database Syst Rev. 2013;8:CD002850.

14. Perk J, De Backer G, Gohlke H, et al. European guidelines on cardiovascular disease prevention in clinical practice (version 2012): the fifth joint task force of the European society of cardiology and other societies on cardiovascular disease prevention in clinical practice (constituted by representatives of nine societies and by invited experts). Int J Behav Med. 2012;19:403-88.

15. Hajek P, Stead LF, West R, et al. Relapse prevention interventions for smoking cessation. Cochrane Database Syst Rev. 2013;8:CD003999.

16. Allen JK, Dennison-Himmelfarb CR, Szanton SL, et al. Community Outreach and Cardiovascular Health $(\mathrm{COACH})$ Trial: a randomized, controlled trial of nurse practitioner/community health worker cardiovascular disease risk reduction in urban community health centers. Circ Cardiovasc Qual Outcomes. 2011;4:595-602.

17. Allen JK, Blumenthal RS, Margolis S, et al. Nurse case management of hypercholesterolemia in patients with coronary heart disease: results of a randomized clinical trial. Am Heart J. 2002;144:678-86.

18. Allison TG, Farkouh ME, Smars PA, et al. Management of coronary risk factors by registered nurses versus usual care in patients with unstable angina pectoris (a chest pain evaluation in the emergency room [CHEER] substudy). Am J Cardiol. 2000;86:133-8.

19. Voogdt-Pruis HR, Beusmans GH, Gorgels AP, et al. Effectiveness of nurse-delivered cardiovascular risk management in primary care: a randomised trial. Br J Gen Pract. 2010;60:40-6.
20. Jorstad HT, Birgelen C von, Alings AM, et al. Effect of a nurse-coordinated prevention program on cardiovascular risk after an acute coronary syndrome: main results of the RESPONSE randomised trial. Heart. 2013;99:1421-30.

21. Jorstad HT, Alings AM, Liem AH, et al. RESPONSE study: Randomised Evaluation of Secondary Prevention by Outpatient Nurse SpEcialists: study design, objectives and expected results. Neth Heart J. 2009;17:322-8.

22. Lim LL, Valenti LA, Knapp JC, et al. A self-administered qualityof-life questionnaire after acute myocardial infarction. J Clin Epidemiol. 1993;46:1249-56.

23. Hofer S, Lim L, Guyatt G, et al. The MacNew Heart Disease health-related quality of life instrument: a summary. Health Qual Life Outcomes. 2004;8:3.

24. Bem DJ. Self-perception: an alternative interpretation of cognitive dissonance phenomena. Psychol Rev. 1967;74:183-200.

25. Berndt N, Bolman C, Mudde A, et al. Risk groups and predictors of short-term abstinence from smoking in patients with coronary heart disease. Heart Lung. 2012;41:332-43.

26. Prochaska JO, DiClemente CC. Stages of change in the modification of problem behaviors. Prog Behav Modif. 1992;28:183-218.

27. Hettema J, Steele J, Miller WR. Motivational Interviewing. Annu Rev Clin Psychol. 2005;1:91-111.

28. Cinciripini PM, Wetter DW, McClure JB. Scheduled reduced smoking: effects on smoking abstinence and potential mechanisms of action. Addict Behav. 1997;22:759-67.

29. Hughes JR, Carpenter MJ. The feasibility of smoking reduction: an update. Addiction. 2005;100:1074-89.

30. Cahill K, Stevens S, Perera R, et al. Pharmacological interventions for smoking cessation: an overview and network meta-analysis. Cochrane Database Syst Rev 2013;5:D009329.

31. Connor Gorber S, Schofield-Hurwitz S, Hardt J, et al. The accuracy of self-reported smoking: a systematic review of the relationship between self-reported and cotinine-assessed smoking status. Nicotine Tob Res. 2009;11:12-24.

32. Aubin HJ, Farley A, Lycett D, et al. Weight gain in smokers after quitting cigarettes: meta-analysis. BMJ. 2012;345:e4439.

33. Lycett D, Munafo M, Johnstone E, et al. Associations between weight change over 8 years and baseline body mass index in a cohort of continuing and quitting smokers. Addiction. 2011;106:188-96.

34. Guillou-Landreat M, Grall-Bronnec M, Venisse JL. Behavioral addictions. Presse Med. 2012;41:1271-5. 